\title{
Social Media and the Hermeneutics of Participation in the Digital Culture
}

\author{
Oscar R. Diamante \\ University of Santo Tomas
}

\section{Abstract}

The pervasive social media and the mobile technologies today, with their features of connectivity, interactivity, participatory, and user-productivity, have provided us new ways of relating with one another and with the world. The participatory culture that social media have helped form stirs up new forms of political participation, economic production, and sociality. However, this also brings about fresh anxieties, tension, and conflict of interests. Critics doubt the optimism and ask whether the goods that social media brings in fact just screen the real negative effects upon our individual character and the social order; thus, their call for a critical theory of the digital culture. In that light, this paper studies the structure of participation in and with social media as part of the hermeneutic phenomenon. Concerned with the status of human understanding, philosophical hermeneutics presents a concept of participation that is integral in the notion of understanding as conversation. The paper also highlights the contrasts between the manipulative tendency of the technical reason and the involved and deliberative character of human practice (praxis). Philosophical hermeneutics, then, as practical philosophy, combats the notion of understanding and participation that is dominated by instrumental and tech- 
nical interest. Thus, in trying to make sense of the participatory aspect and the technological aspect of the social media, there is an emphasis on the element of critical participation in the practice of understanding.

\section{Keywords}

connectivity, conversation, critical, hermeneutics, participation, practice, social media 


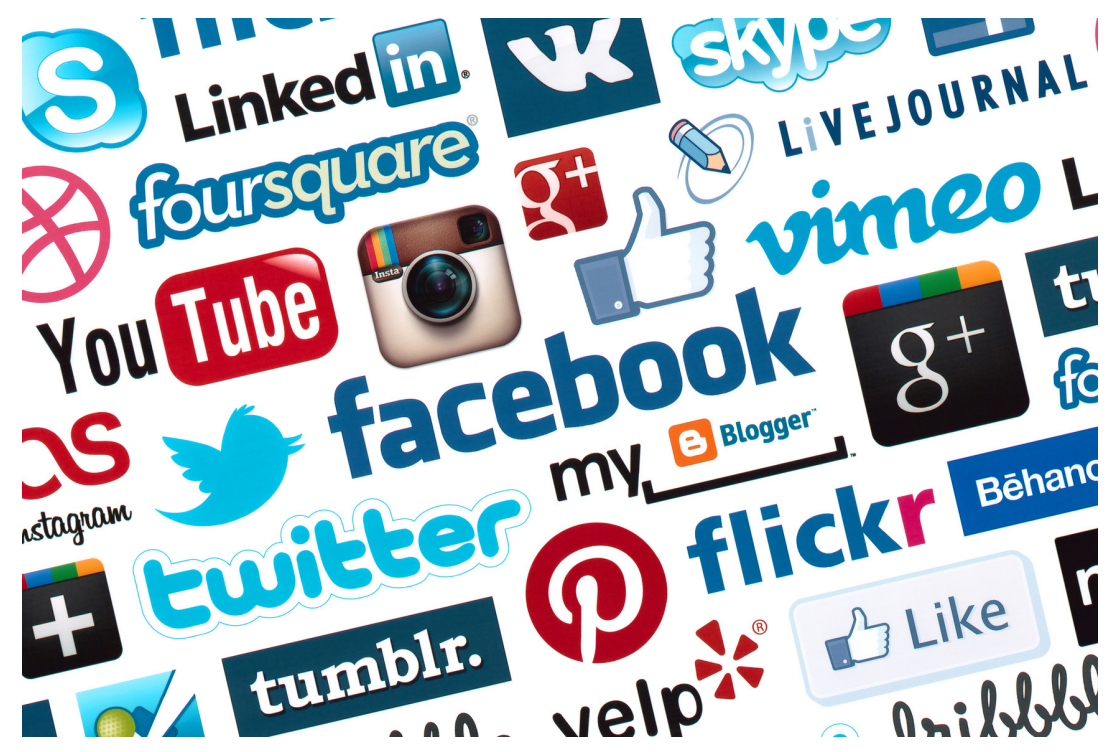

Fig. 1. The pervasive social media and the mobile technologies today, with their features of connectivity, interactivity, participatory, and user-productivity, have provided us new ways of relating with one another and with the world; http://kodaheart.com/ 


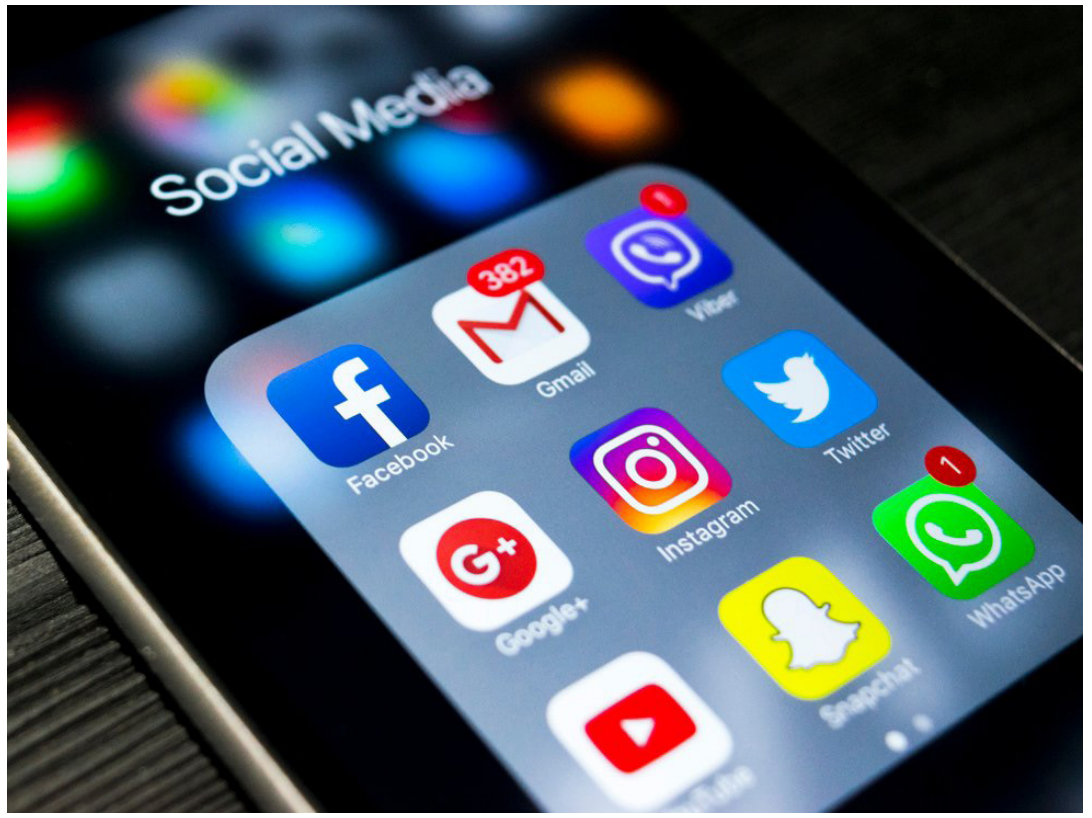

Fig. 2. The social media, collectively, is a kind of technology that provides opportunity for its users to interact among themselves in a new way, mediated only by the Internet and the Web; https://www.amnesty.org.au/ 


\section{Introduction}

We are users of tools, and we have come to think that technology serves as a tool at our disposal. But what happens when technology becomes comprehensive and encompassing (or perhaps overwhelming) such as the case of Information and Communication Technology [ICT]? "In fact," says Luciano Floridi, [the ICTs] have become environmental, anthropological, social, and interpretative forces. They are creating and shaping our intellectual and physical realities, changing our self-understanding, modifying how we relate to each other and ourselves, and upgrading how we interpret the world, and all this pervasively, profoundly, and relentlessly" (6). After a relatively brief span of time from the time when the computer was huge, the ICT seems to have receded into the background as it now becomes ordinary and commonplace. Mark Weiser in 1991 wisely presaged the scenario: "The most profound technologies are those that disappear. They weave themselves into the fabric of everyday life until they are indistinguishable from it" (94). Humans continually upgrade the ICT, and this in turn has constantly formed our social and technological surrounding through the "particular set of technological affordances, a particular set of business models and corporate practices, a particular set of organizations, and a particular set of cultural habits, practices and expectations" (Meikle $\mathrm{x}$ ).

All these pertain to the social media that now has occupied a big role in what we do and how we do things. The social media, collectively, is a kind of technology that provides opportunity for its users to interact among themselves in a new way, mediated only by the internet and the web. The emergence of social media is integrally associated with the rise of Web 2.0 which is basically a dynamic and interactive web compared to the htmlbased static version when it began in 1991. Comparing the two, Jose van Dijck says, '[w]ords like 'interactivity' and 'participatory' described Web 2.0's potential to 'talk back' and send messages instantly, whereas previous media had wielded power over their one-way publishing or broadcasting channels" (10). The "traditional media," like the newspapers and television as well as the commercial companies and organizations that utilized this early form of the web (often later referred to as Web 1.0) produces the content 
(media, products, services, information, among others) that are distributed throughout the web, creating a top-down process of delivery and dissemination. Powered by Web 2.0, the social media (classified as "new media") provides the platforms or software that allow their users to produce content, needing very little technical skills. This time, the inhabitants of the internet, elated over the connectedness, are turned into creators and consumers themselves and become the wellspring of materials that get circulated in cyberspace. In that sense, cyberspace becomes a cultural space and a public sphere where the users' participation is an inherent element for its being. But Web 2.0 is for business purposes, too; it is basically a business model responsible for powering the successes of online commerce after the dotcom bust in 2000.

This development brings about a complex reality where the apparent positive features, like communicating and exchanging documents and objects online, and others simply provide ways to exploit activities in the web for profit. There, questions and issues begin to emerge. Thus, this is not an ideal sphere; the rapid change brought about by the social media "brings fresh anxieties"-like the "anxiety about the authenticity of with whom we may communicate in online networks" (Meikle viii). For Geert Lovink, one of the persistent critical theorists today, "the participatory crowds suddenly find themselves in a situation full of tension and conflict" (Internet Without 1). Second thoughts about the forged connections and online encounters among distant users crop up amidst the shallowness and addictive distractions. Thus, given the phenomenon of the social media today, the embeddedness of these technologies reveals a condition wherein the users' self-understanding is greatly implicated by their participation and their finding of meaning. If we agree with Floridi's profound observation, then we can say that ICT and those that stem out of it, like the social media and the smart handy devices, conjure up the issue of understanding and interpretation. In other words, within the digital culture, the ICT, in spite of its power and promise, is not a transparent reality but still a hermeneutical phenomenon-that is, a situation where the status of understanding is critical in the question of what it is to be human. 
This paper deals with the social media, the structure of participation and hermeneutic understanding. Hermeneutics takes as its point of discussion attempts at bringing into our understanding (or realm of familiarity) unfamiliar situations. Hermeneutics could be an account of bridging the gap between the alien or strange that we strive to understand and the familiar that we already understand; thus, it also encompasses conversations as they involve at least two people trying to make sense of what each other is saying. As is often the case, conflict of interpretations happens in conversations and the need to come to an agreement constitutes a hermeneutical exigency. A hermeneutic understanding involves a recognition that those who participate in the conversation already share a common understanding before they get (or fail) to have a consensus. Advocates of social media studies and users believe the participatory nature of this technological innovation, but critics doubt their use and notion of "participation" that neglects other aspects like decision-making, class and democratic participation (see Fuchs 2014). Philosophical hermeneutics as a philosophical activity is also praxis, an understanding that is expressed in real life and action. ${ }^{1}$ As emphasized by Gary Shapiro and Alan Sica, "the broad hermeneutical aim is to make such understanding meaningful for life and thought" (Hermeneutics 4). Thus, it is under this view that notions of participation and understanding in the context of the social media and the wider world of the digital culture shall be analyzed.

\section{The Social Media}

The convergence of the internet and communication has led to tremendous advances in connection, communication, and automation (computer technology) that has brought about significant consequences in the production, distribution, and management of information. All these help create the digital culture, wherein its material artifacts include computers, smart mobile devices, digital media, networks, data warehouses, broadband connectivity, among others. The integration and complementarity of these things, not to mention their overlapping developments, shape the new technologies that impact on our social reality. For these are not mere technologies; they entail 
social relations and processes, promptly transforming the character of our culture today. They usher in new spaces for interactions and mediations that challenge social theorists as well as corporate thinkers to reflect on social change and the consequences for development. In particular, an important thing that emerges in this digital age is social connectivity or online sociality that draws many users into creative and persistent interactions, unhampered by physical distance and occasion (maybe an executive is in the middle of a formal meeting but occasionally sends messages to his mechanic regarding the repair of his engine; or likes a Facebook post of his girlfriend, and others). These interactions take along myriad of possible artifacts-from personal, religious, cultural, economic to social and political-that get shared in multiple directions and in a fast pace. Thus, forming a new dimension in human sociality-where the online and offline blend-serves as context for self-understanding, inasmuch as the new digital media technologies have emphasized their participatory aspect.

People's practices that are mediated by digital technology have changed (not to say advanced) in just a short period of time. One highlight of the digital media is its salient features compared to the old broadcast media. ${ }^{2}$ The social media is an online media and is interactive owing largely to its being hypertextual and hypermediated. The prefix "hyper," though originally coined to refer to being linked or having a link within the web, means "excessive," perhaps precisely because a text or medium leads one to another text or medium, then to another, and to another, and others creating rhizomic movement that leaves no center and remains open-ended. However, the social media, even goes beyond the "hyper" feature. In social media, the users have the ability to produce content and spread it. In the internet "media spreads," say Henry Jenkins, Sam Ford, and Joshua Green, as they argue for the spreadability model in describing how content within the network get created, remixed, reframed, or shared, and others. "If it doesn't spread, it's dead." 3 They claim that the rapid and widespread circulation of media content is based largely on the "social motives of those who are actually doing the spreading," and in the process of being distributed from culture to culture, the same content is being remade, reinterpreted and transformed (Jenkins, 
Convergence Culture 296). In this environment, brand producers or companies need to understand the new dynamics of production and consumption where the grassroots now have leverage in the overall process of content creation. As the emphasis on the customers or audiences' big role in the production and circulation of media is clearly pointed out in the book, it can be said that even technological innovations, like the media platforms, are shaped in large part by grassroots movements and perceived desires. In the new media ecology, spreadability provides diversified meanings and experiences and reflects practices of participatory culture. Thus, this also increases the opportunity for opening up to new perspectives and developing empathy for perspectives of others (Jenkins, Convergence Culture 304).

The status of being at the same time producer and consumer is the result of the blurring of boundaries between producers-creators of content and cultural artifacts-and consumers, the users, audience or buyers of the products. In The Third Wave (1984), Alvin Toffler already coined the term "prosumers," referring first to people who consume what they themselves produced, such as what occurred in the First Wave, then to users of the kind of products like the DIY (Do-It-Yourself) in the Third Wave. In the context of the new media technology, Alex Bruns' complementary term "produsage" is meant to break away from the "producer $\rightarrow$ distributor $\rightarrow$ consumer dichotomy" inherent in the industrial economic model, to present an appropriate term that fits the informational economic models. Bruns says that:

[I]n such models, the production of ideas takes place in a collaborative, participatory environment which breaks down the boundaries between producers and consumers and instead enables all participants to be users as well as producers of information and knowledge, or what I have come to call produsers (275-284).

Bruns emphasizes not only the role of users as producers, but also the elements of collaboration and continuous building and extending of existing content, like in the case of Wikipedia and multi-user games. The new concept (or even already a phenomenon) produsage, just like any other neologism, helps in the understanding of the internet in general and the social media in 
particular as it highlights several processes. First, greater consumer influence is manifested as feedback processes between producers and consumers are encouraged. Second, the more innovative communication and information technology favors the "information pull" method of access to information which in turn encourages produsage. Third, through the new media platforms, the production and distribution of information and cultural artifacts are much more widely available or democratized, as also noted in The Spreadable Media. Fourth, more networking sites enable a collective means of organization and engagement. And fifth, content is digital which is easily produced, reproduced, remixed and distributed or spread; and it can be endlessly used by all (Miller 87).

These processes are manifestations of the convergence that has fundamentally characterized the coming together of communication, information, and computer technology. Conceptual models such as "spreadable media" and "produsage" in understanding the digital culture present an opportunity, wider role, and greater agency of the users. Now, they are not merely passive receivers of products and services; they are also determinants of the overall content of the internet. In a way, the digital culture has become a gigantic factory which does not have a central authority but an interplay of interests and technological enablement. Its great impact upon capitalism in the post-industrial economy has been duly noted by critics. Many say that changes in the production opportunities ushered by the information technology do not really substantially break-up the capitalistic structure and agenda; but some also point out that the shift to a network structure of the economic enterprise and the lessening of the direct control by the capitalist upon production and distribution already constitute a significant change. Joe Karaganis' descriptions for search engines and digital technologies, in general, equally apply to social media. Using Deleuzian concepts, he says:

[d]igital technologies are powerful forces of deterritorialization-of disembedding knowledge and culture from existing institutions, practices, and geographies-but they are also tools of continuous social and political reterritorialization, as borders are redrawn, new institutions and structures emerge, and new forms of control are established (11). 
Although it has all the qualities so far attributed to the digital media, the social media, Graham Meikle points out, differs from the digital media in general for it includes the "dimension of personal communication that is so central to social media" (6). With a social media account, the user connects with others and let others interact with her personally online. Since each has her/his own network of friends or contacts, her/his personal communication with any of them generally generates visibility thereby making it public communication as well. This description of personal communication that converges with the public puts the likes of Wikipedia outside the category of social media. A trivial differentiation in so far as the discussion here is concerned, however, it points to what is essential-which is the sphere in which interactions and conversations can happen-when Meikle defines social media "[as] networked database platforms that combine public and personal communication" (6). The emphasis on the added feature of personal communication and public visibility highlights the cultural pattern that blends the personal, private, ordinary with the professional, public, and formal. From one perspective, this is a kind of widening of the socio-political sphere, encouraging and enabling free expression, creative imagination, new associations, and conversations. But from another view, this can also be another occasion for exploitation of unpaid labor, or economic opportunism.

Jose van Dijck's discussion in the Culture of Connectivity: A Critical History of Social Media presents another aspect that needs to be highlighted in the understanding of social media. Van Dijck uses Haenlein and Kaplan's definition which says that social media is "a group of Internet-based applications that build on the ideological and technological foundations of Web 2.0, and that allow the creation and exchange of user-generated content" (4). ${ }^{4}$ While Web 2.0 platforms are user-centered and facilitate interactivity, collaboration, and communal activities, they are also coded systems that automatically manipulate connections. The technical aspect of social media cannot be downplayed insofar as "sociality coded by technology renders people's activities formal, manageable, and manipulable, enabling platforms to engineer the sociality in people's everyday routine" (van Dijck 12). The conflation of human connectedness and automated connectivity has also shifted the basis 
valuation from quality (the kind of friends and intimacy developed) to quantity (the sheer number of friends). Online sociality is in fact techno-social where platforms are the conditions for social interactions. Apparent in van Dijck's presentation is the clash between user tactics and platform strategies. Thus, from all indications, defining social media is not an easily settled issue; the varying points of view, exhortations, and criticisms reflect the still ongoing debate.

\section{Participation in Social Media}

According to Nico Carpentier, a professor in communication studies, "the concept of participation is one that emerges throughout the social." $\mathrm{He}$ locates the articulation of participation in democracy, development, spatial planning, art and museum, and communication (10). What Carpentier asserts is true whatever he means by social. Among many things, Carpentier's bold assertion is that participation is really about power. In the political order, the relevance or importance of participation goes back to its political root. Participation is legitimate and important because the imbalances of power between the ruler and the people can be minimized by the logic of participation. An authoritarian regime concentrates power in the ruler and participation of the governed is almost absent. The maximum participation is when each individual has equal power to determine the outcome of one's decision. When power is absent, then there is no participation to talk about. The notions of access and interaction are differentiated from participation because the first two do not involve an act from the participant to effect a change upon the other party. Participation involves co-deciding with others. Such a framework, when applied to media (broadcast), presents a situation wherein audience-participants need to negotiate their way within the balance of power usually determined by structure (of the media) and the privileged status of the professional practitioners. Accordingly, Carpentier states that: "The power play that is seen at work in a highly fluid and contingent context creates the need for constant negotiation and care in order to protect the vulnerable power equilibrium between media professionals and participants" (425). Obviously, Carpentier's case reference could not be 
made to refer to social media where the structure of audience engagement is significantly different.

In his Convergence: Where the Old and New Media Collide, Henry Jenkins illustrates how media transitions from the broadcast media toward convergence brought by the cultural process alongside the development in communication and digital technology. In his book, he argues for the new trend for technology, media industry, audience, content creators with respect to how media content flows-Convergence. "By convergence, I mean the flow of content across multiple media platforms, the cooperation between multiple media industries, and the migratory behavior of media audiences who will go almost anywhere in search of the kinds of entertainment experiences they want," states Jenkins (2). Brought about by this new phenomenon is the participatory culture which "contrasts with older notions of passive media spectatorship" (3). Here, the roles of media producers and consumers are not separate but rather they converge. The words prosumers and producer reflect this convergence which promotes participation more than spectatorship. In general, we consider the users as participants who interact, collaborate, engage, and others, according to a set of rules different from what we have known. Jenkins talks of the collective intelligence, a term by French cybertheorist Pierre Lévy, as product or process wherein participants get to interact, confer, discuss, or converse with one another. He claims that collective intelligence is an alternative source of power which plays a great part in the meaning-making in the popular culture.

In Spreadable Media, Jenkins, Ford, and Green talk of the "spreadability as the potential ... for audiences to share content for their own purposes ..." (3). This notion connotes more the act of circulation rather than distribution of media. Accordingly, "audiences are making their presence felt by actively shaping media flows, and producers, brand managers, customer service professionals, and corporate communicators are waking up to the commercial need to actively listen and respond to them" (2). This view takes note of the growing prominence of the "grassroots audience,"-the usual, ordinary users-and its role or part that get the attention of the media owners and creators within the dynamics (or logics) of the digital environment. We can 
relate to this the rise of social networking platforms that facilitate greater flow of sharing and exchange. Jenkins, Ford, and Green note that "... networked participation also forces media companies and brands to be more responsive to their audiences" (175). Thus, even in the sphere of audience and technical creators, participation has led to not only to concrete results (creating and innovating digital tools) but also toward mutual recognition. Part also of the argument, with the model of spreadability, is the emphasis that participatory culture should not be understood as being determined only or largely by the technology, say of the social networking sites. The argument points more to the logic of the interaction and relation and the practices that emerge. Thus, participation is not limited to creating and circulating artifact; it also involves reading, commenting, sharing, and posting.

\section{The Social}

A critical look upon the concept of "social media" can turn to the meaning and significance of the word "social." Does it hold a great significance that fosters greater solidarity and critical engagement? Basically, media in general are social inasmuch as they are invested with human labor and concerned with social matters-that is, issues that touch upon the people and their relations. There was a time when the social was related with the expression of power, class struggle, and protest. The social was a word used in line with politics, interests, work, class awareness, and emancipation. Today, the social is more connected to the techno-cultural not to a revival of the social in the revolutionary era. According to Geert Lovink, "nowadays, the social manifests itself in a network form. Its practices emerge outside of the walls of the twentieth-century institutions, leading to a corrosion of conformity. The network then becomes the actual shape of the social" (Social Media Abyss 16-17).

Here, the social is more about the quantitative (counting "social facts"), about how much the network has reached and carried the users into its fold. People count their followers in Twitter, their likes and friends in Facebook, their contacts in email. Lovink also asserts that, 
[t]he term 'social' has effectively been neutralized in its cynical reduction to data porn. Reborn as a cool concept in the media debate, the social manifests itself neither as dissent nor as subcultural.... The social is precisely what it pretends to be: a calculated opportunity in times of distributed communication ("What Is the Social").

It appears that the meaning of social media involves the tension between the building of social life guided by the ideal of the common good and the fact of technological culture hinged upon the power of the technology of information and communication. This dual aspect is evident in the way van Dijck describes the meaning of "social." He says, "The meaning of 'social' hence seems to encompass both (human) connectedness and (automated) connectivity-a conflation that is cultivated by many CEOs...." (12). The question whether the advancement of technical ability and the increase in information necessarily lead to the strengthening of the social reason is very important.

\section{Hermeneutics: The Problem of Understanding and the Notion of Participation}

In philosophical hermeneutics, dialogue, understanding, participation, and practice are key concepts in articulating how human persons make sense of their relationships with others and with the world. In elaborating this philosophy, Hans-Georg Gadamer asserts that hermeneutics is basically an art of interpretation and understanding which has its beginning in the interpretation of the bible, law, and literary texts. Noting these early forms of hermeneutics, Gadamer then traces hermeneutics' development through the establishing of its universal or philosophic character to its ontological foundation as influenced by Heidegger's "hermeneutics of facticity." Rather than follow an intellectual or epistemological notion of knowledge, Gadamer takes understanding more as a practical know-how, a sort of skill when one makes one's way through life; a practical knowledge of a being which is, in Heideggerian terms, "a being that is always concerned by its own being." He argues that hermeneutics is a practical philosophy based on the notion of philosophy by Aristotle. Gadamer explains how Aristotle considers philos- 
ophy as practical philosophy as opposed to the mathematical knowledge which is the theoretic knowledge or episteme for the Greeks (Reason in the Age of Science 89). For Aristotle then, philosophy is also political philosophy which is essentially a practical wisdom (phronesis) in that it is concerned with articulation of the life in the city (polis) with power to decide or to make "preference" (prohairesis) with respect to the good. Correlatively, the concept of practice (praxis) is not to be opposed to the concept of science and theoria, but perhaps to the acquired skill of the expert which is referred to as techne. Gadamer often emphasizes that the modern notion of practice or practical as some sort of application of a general theory (that is often formulated in pure science) is not what Aristotle nor even Plato teaches. ${ }^{5}$ Practice always begins with what is, just as understanding does not begin with zero or pure innocence. Thus, hermeneutics, inasmuch as it is a practice of understanding grounded in life's concrete situation and to which it is repeatedly transposed, is practical philosophy. Gadamer claims that it is the task of philosophical hermeneutics to disclose the full scope of the hermeneutical dimension of human understanding as well as to present its significance to our understanding of the world in all the forms this understanding takes-

from interhuman communication to manipulation of society; from personal experience by the individual in society to the way in which he encounters society; and from the tradition as it is built of religion and law, art and philosophy, to the revolutionary consciousness that unhinges the tradition through emancipatory reflection (Philosophical Hermeneutics 18).

Therefore, it is then within its scope that with philosophical hermeneutics, one could undertake a hermeneutical reflection upon the phenomenon of social media and its effects on our self-understanding as users or participants in particular, and, as social agents in general. The basic question that we bring up with respect to social media is this: What is the status of understanding in which our social being is brought to greater light and which builds the social reason?

Geert Lovink laments how critical studies cannot keep up with the fast changing information technology. With the IT, the society is way ahead of 
its theorists (including Lovink, as he admits himself). The object of study, he says, is in a constant state of flux:

The realization that theory in the form of detailed case studies is condemned to history writing can induce a state of depression and drag us further into a pharmacological state of mind, as Bernard Stiegler calls it. Along with the demise of French theory, there is a clear lack of guidance (Internet Without a Cause 7).

But the need for theory is still the urgent call in our situation today. The same is echoed by Christian Fuchs in his books asserting that understanding social media requires asking and engaging with many theoretical questions: "Social theory not only allows us to understand the meaning of concept, it also allows us to ask important questions about the world and it can be fun to theorize and to discuss theories with others" (Social Media 7). But the peril in burrowing into social media studies, warns Lovink, is that: "the networks without cause are time eaters, and we're only being sucked deeper into the social cave without knowing what to look for" (Internet Without a Cause 6).

With regard to Lovink's warning, Gadamer's take on “theory” is very helpful. For Gadamer, hermeneutics is both theoretical and a practical task because it plays a role in every instance of the desire to know (theory or science in general) and the demand to bring about an understanding with others in the community (praxis). The universality of hermeneutics involves the task of integrating all the sciences and deploying them wherever they may be applicable. "It has to bring everything knowable by the sciences into the context of mutual agreement in which we ourselves exist" (Gadamer, Reason in the Age of Science 136). The usual contrast that we are used to between theory and practice is misleading; they are not exactly opposite nor opposed. When Gadamer traces the idea of theory, a word which has gained fame in relation to science, there he finds that participation is an essential task of it. Theoria is "witnessing;" it is about being a witness in a festival as participant and validating it. According to Gadamer, "[i]t seems helpful to recall here the original Greek sense of theory, theoria. The word means observing (the 
constellations, for example), being an onlooker (at a play, for instance), or a delegate participating in a festival" (In Praise of Theory 31).

So, participation is integral in human studies where truth and meaning emerge from the thoughts and activities of the community. The ideal of knowledge for modern science is objectivity which is essentially standing apart from its object but also overcoming and dominating it. Its opposite, the ideal of participation, is one where prior relations with their object remain essential for the human sciences. Likewise, in understanding social media, one cannot not ignore the fact that participation is a much contested aspect of its nature. In the case of social media, the technical structure opens up a big possibility for practice in the working up of "social reason." There is often an interplay between the technical reason and practical reason. Programmers of platforms draw their ideas from the desires and movements of the users of media, both online and offline. They do not begin from scratch for otherwise their project will flop; and with this, they need to be keenly observant. Their creative imagination is stimulated and inspired against the background of shared aspirations. Simulation, a process of imitating the user's usual movements and habits, is essential to coding because the appeal of the platform is its being "user-friendly," meaning, the user can easily appropriate it to their quotidian habits. Thus, while in a way social media directs the users to activities that are not merely channeled but "programmed" with a specific objective, social media platforms themselves are already negotiated coding that relies on the desires and actions of the users, and the same platforms cannot not remain static since the movement of sociality is dynamic. Eventually, one platform will get rejected or abandoned by users when it cannot cope with the changing culture, or replaced by a much better one by virtue of adaptability. The idea of participation here is all over the place for the programmers as well as for the users.

Online, and even offline, we encounter new vocabularies, like "googled," "netizen," "facebook," "youtube," and others. What this practice reveals is that inventions or innovations are not completely novel but always connected to the tradition and to the language that people speak. This presupposes that creators of platforms and media participate and are dependent upon the 
ongoing movement of understanding. Inasmuch as the technical terms that they construct can be anything since meaning can be entirely arbitrary, they may eould have created words that are totally unknown or foreign to anyone else. That the terms such as those mentioned above are what they have come up with betrays their dependence upon the linguistic tradition they share with others. Nicholas Davey explains that with regards to participation in hermeneutics,

[a] principle of original dependence is asserted: on the one hand I could not utter the word I do were it not for my dependence upon linguistic frameworks that transcend my individual consciousness; on the other, those meanings whose extent transcend my awareness cannot maintain their being unless I participate in their play (103-104).

Thus, a computer geek, even though how odd her/his appearance is, does not really break away from the reach of tradition which is the language that she/he speaks.

\section{Conversation and Participation}

Gadamer's model for hermeneutic understanding is dialogue or conversation. In Truth and Method, Gadamer insists on the dialectical nature of understanding. Understanding or the discovery of truth is not one which can be mastered or captured at once. Understanding can be obtained through the dialectic of question and answer which properly takes place in dialogue. For Gadamer, understanding is always coming into agreement or an understanding about something. This process is not a matter of knowing one another's inner thoughts and then one understands the other. Since understanding is always an event, it is in fact a conversation which, says Gadamer, is a process of coming to an understanding (Truth and Method 385). Social media presents us various innovative ways of bringing people into conversations. The versatility of these apps (i.e., applications or software programs) provides some impetus for their users to be creative or adaptive to the apps' limitations, like Twitter's 140-character limit. 
But is there really genuine conversation in social media? Surveys provide the dismal fact that a big percentage of the posts or interactions is "garbage." But so are a lot of interactions or "talks" of people outside the online setting. In other words, chatters, jokes, idle talks, and others can happen anytime where there is reciprocal interactions between people. However, even in those cases, subjective agency only comes after the "lure" or "intimidation" of the subject matter. Certainly, there are matters that get discussed in social media; there are also occasions where real conversations take place. Protest movements such as the Arab Spring in the 2010s and Occupy Wall Street in 2011, in which social media was said to have had a role, certainly involved participants that listened to and talked about issues. This is the age of Anonymous, Wikileaks, Snowden, Malware attacks on network companies, Presidential election campaigns, trolls-all of which draw global attention and certainly stir up conversations in social media. ${ }^{6}$ "To conduct a dialogue," says Gadamer, "requires first of all that the partners do not talk at cross purposes... The first condition of the art of conversation is ensuring that the other person is with us" (Truth and Method 375). In real situations, conversations can take place in not so specifically-defined roles: online activists may be on one side but it is not easily clear who is on the other. What is more important in a true conversation is that each one is open to the other. No one has control of the conversation. In conducting a conversation, what really happens is that the flow of conversation lies not so much within the will of either partner since, as Gadamer says, a genuine conversation is never the one that we wanted to conduct (Truth and Method 383). Thus, participants in the conversation cannot rightly claim that one sets the direction of the conversation with the other forced to abide by it. Rather, while it is possible that a participant dominates the conversation and one gets the answers that one wants from the other, we may doubt whether there is real conversation. So in that case, it is doubtful if both participants ever come to an understanding about their issues. "To conduct a conversation means to allow oneself to be conducted by the subject matter to which the partners in the dialogue are oriented" (Truth and Method 383). Real conversation is one when partners or participants are carried away by that about which they come to dialogue 
in the first place. The centrality of the subject matter (sache) in the conversation shifts the notion of knowledge from the dominance of the subject or of the object. Thus, it cannot be said that one participant can direct the conversation to the course that one prefers thereby dominating the other participants. The dialogue will then be based on the aggressiveness, strategy, position, and others, of the one partner with respect to the other.

The picture of online discussion in social media easily comes to mind. This discussion would be between the followers of a certain political figure or platform, or maybe of users with common opinion about a case shown in the CCTV video and one or two users holding a different, opposite opinion. As is often the case, the dominant and aggressive posts come from one party by their sheer number trying to overwhelm or drown out the other to the point that one's contention would not be heard or taken into consideration. The end result is that the majority or dominant users only hear themselves and never the other. Worse still is the case of fake accounts. Ressa's investigative report, "Weaponizing the Internet" series, unravels the menacing effect of fake accounts that are used to advance propaganda and fight perceived political opponents. ${ }^{7}$ The report says:

One account alone we determined to be fake was connected (as of October $6,2016)$ to about 2.9 million members of various overseas Filipino groups associated with Ferdinand "Bongbong" Marcos Jr, and other hobby groups. Another fake account was linked to over 990,000 members of groups supporting President Rodrigo Duterte, and still another was connected to an estimated 3.8 million members of various overseas Filipino organizations and buy-and-sell groups. ${ }^{8}$

Once the fake account sends a post, it will be delivered to thousands of Facebook accounts and can create a false account of reality, thereby, damaging the conduct of understanding for many.

From the point of view of hermeneutics, fake accounts like these do not belong to the practice of conducting a conversation. Are they participants in the real sense as featured above? Rather than real participants, they are disruptors-they disrupt real conversations, thus ultimately, understanding 
too. Fake accounts are there not, as earlier described, for a true conversation but for something materially rewarding, or even for something that borders on unreason. But they can be employed to serve some goals connected to interest for power in which they function like bots, similar to what has been happening in Philippine society since the Presidential election in 2016. The internet is also populated by mischief-makers and deviants like the trolls, spammers, flamers, hackers, identity thieves, groomers, sock puppets, stalkers, and pirates (Brabazon 11). Fake accounts can be handled by any of these deviants, but especially by the trolls and sock puppets.

\section{The Digital Culture: The Question of Practice vs. Technique}

We can employ the notion of practice that Gadamer wants to rehabilitate and which has changed with the modern notion of science. As Gadamer wrote in the late '60s and early '70s, he did not see the growth of information and communication technology that we have today or even a decade ago. But he had caught some of its early manifestations. He noted the fact that it was no longer the age of massive machines, but "the age of cybernetics, of regulative systems, of self-steering systems" (Reason in the Age of Science 84). He mentioned of many other advancement in technology whose power overextended to the point of threat to human existence on earth. The general experience vis-à-vis such threat appealed to practical reason to make us aware of "the limits of our technical rationality: the ecological crisis." Gadamer is critical of the technical reason and its manipulative capacities. If he had stayed much longer to witness the progress of information technology and the emergence of the social media, what would have been his reflections on all these? Perhaps it is our task to surmise the answer based on our knowledge of his ideas and the leads that he had issued.

The lead is about what he said regarding the technical rationality, the rationalization of our lives in the society and the notion of practice. According to Gadamer, the technologizing of nature leads to the rationalization (also in Weberian sense) of our social life. Rationalization of society consists in technical ordering of lives, technocratic control by experts to whom people have recourse and to whom they look "for the discharging of 
the practical, political, and economic decisions one needs to make" (Reason in the Age of Science 72). Facebook's Mark Zuckerberg apparently felt this role when he told his audience at the South by Southwest Interactive Festival in 2008: "There are a lot of really big issues for the world to get solved and, as a company, what we are trying to do is to build an infrastructure on top of which to solve some of these problems" (qtd. in Morozov ix). The social media phenomenon, given its and ICT's technical aspect, would more or less fit the description by Gadamer. The fully technologically-mediated social interactions maybe very attractive for social management and for economic production in Capitalist society, but the increasing technical ordering of such interactions may actually weaken them, as well as, the community. Digitization is almost tantamount to fragmentation of meaning and symbol, thereby, threatening the possibility of interpretation or understanding. According to van Dijck, "Connectivity quickly evolved into a valuable resource as engineers found ways to code information into algorithms that helped brand a particular form of online sociality and make it profitable in online markets..." (4). Data mining, "the process of sorting through large data sets to identify patterns and establish relationships to solve problems through data analysis," dominates the practice of experts that is making its way to economics, politics, and even education. Eventually, as what is now gradually happening, personal and institutional decisions will be largely defined by data analyses. Behind our gestures and searches in the internet, apps and browsers gather and record data, and these are best captured in social media where we are most expressive and open about our desires and tendencies. These are all incorporated in the concept of "big data," which is introduced to make "sense of the large datasets to identify social patterns in order to make economic, social, and legal claims" (Barassi 138). Many advocates of participatory culture in social networking sites, or social media platforms, need to realize that in spite of the affordances that these sites provide, the complementary limiting and restricting features of these technologies prevent real practice and participation. One way or another, digital technology as a whole (mobile devices included), wipes out the "flexibility in our interchange with the world" and with one another. Gadamer had also 
warned about this as he stressed: "Whoever makes use of technology-and who does not?-entrusts himself to its functioning" (Barassi 71).

In contrast to the technical, Gadamer's hermeneutics articulates and promotes the practical. While the technical automates, assures accuracy, secures objectivity, and predicts results, the practical requires participation, involvement, deliberation, interpretation, and subordination to common ends. The accuracy and objectivity of technical knowledge are is often de-contextualized and therefore, taken out of the context of participation. While the practical may not attain accuracy and objectivity, it proceeds by building upon the "self-evidence" of the concrete whose inner clarity we all share. Practical reason does not proceed with well-thought-out plans, unlike the technical reason that executes a program with determined reactions and results. Practical reason builds upon itself from within but grounded in ethos. Thus, practical knowledge is something we grow within ourselves along with others with its indetermination and prejudices. Practical wisdom is not teachable unlike as scientific or technical knowledge is; it but can only be learned or formed in oneself in praxis. Furthermore, it is capable of questioning its own presuppositions and prejudgments while remaining open to other matters as it participates in the event of tradition. Just as a person in the practice of understanding needs to participate in the subject of investigation as well as in its meaning, so too with her engagement in social media. Learning the ways of the gadgets and the particular apps may be provided by a manual that can be used over and over by different users; but learning the ways of life to become an experienced person cannot be captured by any manual or textbook, nor can experience be completely taught by the master. Rather, in practice alone can it be learned.

\section{Critical Participation in Social Media}

What is then supposed to be our engagement with social media and with others in these social networking sites? First of all, as the techno-optimists and the users rejoice over the re-energizing of the internet after the dot com disaster, as the Web 2.0 platform of platforms brings about the now much-celebrated social media, are we not actually being drawn into the age of 
what Lovink calls the "platform-capitalism"? Or perhaps "digital capitalism" (Fisher 2010; Barassi, 2015)? Lovink himself calls for "a critical theory of intermediaries that is technical, cultural and economic in nature" (3). Others take the forms of network studies, platform studies, internet studies, and social media studies, depending on the focus guided by what is viewed as the most crucial phenomenon confronting us. Second, within social media, one gets to participate in and experience constant interactions of varied forms like sharing sentiments and opinions with those having the same interests, contributing one's ideas on art works, commenting on blogs or news items and answering others on certain political issues, engaging other users in a debate about religious practices and beliefs or about political policies or laws. At a certain point, one has to realize that in most cases, experience in social media is an experience of the foreign, of the Other, contrasting and challenging herself, her beliefs, and ideas. One may ask oneself, do I have to consider them as other or just an aberration, an irrationality that must be stamped out because they are dangerous or simply wrong? If one is ready to defend her political or even intellectual convictions and also determined to destroy the wrong beliefs and invalid claims of others, then one can get really embroiled in the discussions in social media. It seems, one might think, that there is a huge chance to bring change considering that social media produces a multiplier effect. After all, one is already involved when one chooses or happens to read blogs, read posts in Facebook, in Twitter, or register in Disqus or other comment-hosting apps. In this case, a critical stance toward participating in social media is just a proper attitude. A critical attitude and a critical mind will be needed to make one's way in social media or the internet, in general, for apparently everything that comes down into it is not what it seems.

So in both cases cited above, social media as the techno-phenomenon, as a form of "platform capitalism" or "digital capitalism," and the world of interactions as one participates in social media, one must always have critical understanding. In philosophical hermeneutics, the critical element is immanent within the process of understanding even as Gadamer emphasizes that understanding is always a dialogue with tradition. Although social media 
cannot be easily regarded as traditional, nevertheless it comes down as part of the overall heritage or legacy, although it is itself already a critical appropriation of the tradition. Social media platforms are themselves a form of interpretation, that is, by their programmers as they participate in ongoing dialogue with users, stakeholders, and the business climate in general, as indicated above. Critical reflection consists of clarifying and negating false prejudices and settling with matters that answer prior questions. By being aware of and putting this particular phenomenon in the dialectic of question and answer, the users may be emancipated from the effects of the instrumental rationality that works in these digital platforms. It is inherent in hermeneutic understanding that it involves "critical appreciation" that guards us from being bewitched into laziness and getting blindly accessorized. In this way, it can be readily acknowledged that these platforms are meant to advance a value or to eradicate anomaly while at the same time drawing back behind that which works as its ideological grounding since nothing can be fully transparent. Thus, the whole thing is always an ongoing process, wherein each time understanding occurs, it is a particular understanding attributed to the interpreter, or, particularly in this case, to the user. 


\section{Notes}

1. This was further elaborated by Gadamer in "Hermeneutics as Practical Philosophy" in Reason in the Age of Science, translated Frederick Lawrence, Massachusetts Institute of Technology P, 1979, pp. 88-112.

2. See Vincent Miller, Understanding Digital Culture. (London: Sage Publications, Ltd. 2011).

3. See Henry Jenkins, Sam Ford, and Joshua Green, Spreadable Media: Creating Value and Meaning in a Networked Culture (Postmillennial Pop). Kindle ed., New York UP.

4. See original source: Andreas M. Kaplan and Michael Haenlein, "Users of the World, Unite! The Challenges and Opportunities of Social Media," Business Horizons 53, 2010, p. 61.

5. See Hans-Georg Gadamer, The Idea of the Good in Platonic-Aristotelian Philosophy, translated P. Christopher Smith, Yale UP, 1986.

6. In Linda Herrera, Revolution in the Age of Social Media: The Egyptian Popular Insurrection and the Internet, Verso Books, 2014, the author debunks the claim that the Arab Uprisings are "Facebook revolutions"; but instead she claims that "the generations coming of age with social media, virtual values, and virtual intelligence have a great capacity to unlock the mechanisms of ideology" (qtd. in Geert Lovink, Social Media Abyss, p. 192)

7. Visit http://www.rappler.com/newsbreak/investigative/148347-fake-accounts-manufactured-reality-social-media and other linked pages.

8. Visit http://www.rappler.com/newsbreak/investigative/148347-fake-accounts-manufactured-reality-social-media and other linked pages. 


\section{Works Cited}

Barassi, Veronica. Activism on the Web: Everyday Struggles Against Digital Capitalism. Routledge, 2015.

Baym, Nancy K. Personal Connections in the Digital Age. Polity P, 2015.

Beasley, Berrin, and Mitchell R. Haney, editors. Social Media and the Value of Truth. Lexington Books, 2015.

Brabazon, Tara. Digital Dialogues and Community 2.0: After Avatars, Trolls and Puppets. Chandos Publishing, 2012.

Briggs, Asa, and Peter Burke. A Social History of the Media: From Gutenberg to the Internet. Polity P, 2009.

Bruns, Axel. "Towards Produsage: Futures for User-Led Content Production." Cultural Attitudes Towards Technology and Communication 2006: Proceedings of the Fifth International Conference on Cultural Attitudes Towards Technology and Communication. Edited by Fay Sudweeks, Herbert Hrachovec, Charles Ess, School of Information Technology, Murdoch University, 2006, pp. 275-284.

Bruns, Axel, Brenda Moon, Paul Avijit, and Felix Münch. Towards a Typology of Hashtag Publics: A Large-Scale Comparative Study of User Engagement Across Trending Topics. doi:10.1080/22041451.2016.1155328.

Carpentier, Nico. Media and Participation: A Site for Ideological-Democratic Struggle. Intellect, 2011.

---. “The BBC's Video Nation as participatory media practice: Signifying everyday life, cultural diversity and participation in an online community." International Journal of Cultural Studies, 6(4) 2003, pp. 425-447.

---. "The concept of participation. If they have access and interact, do they really participate?” Communication Management Quarterly, vol. 21, 2011, pp. 13-36.

Carr, Nicholas. The Shallows: What the Internet Is Doing to Our Brains. Kindle ed., W. W. Norton \& Company.

Castro, Fleire. "Social Media and Digital Stats in the Philippines 2016." 31 Jan. 2016, http://fleirecastro.com/guides/social-media-and-digital-stats-in-the-philippines-2016-wearesocial-data/. Accessed 18 Feb. 2017.

Chayko, Mary. Superconnected: The Internet, Digital Media, \& Techno-Social Life. SAGE Publications, Inc, 2017.

Davey, Nicholas. Unfinished Worlds: Hermeneutics, Aesthetics and Gadamer. Edinburgh UP, 2013.

Donelan, Helen, Karen Kear, and Magnus Ramage. Online Communication and Collaboration: A Reader. Routledge, 2010.

Fisher, Eran. Media and New Capitalism in the Digital Age. Palgrave Macmillan, 2010.

Floridi, Luciano. The Fourth Revolution: How the Infosphere is Reshaping Human Reality. Kindle ed., Oxford UP, 2014. 
Fuchs, Christian. Culture and Economy in the Age of Social Media. Routledge-Taylor \& Francis Group, 2015.

---. Social Media: A Critical Introduction. SAGE Publications Ltd., 2014.

Gadamer, Hans-Georg. Gadamer in Conversation. Translated and edited by Richard E. Palmer, Yale UP, 2001.

---. In Praise of Theory. Translated by Chris Dawson, Yale UP, 1998.

---. Philosophical Hermeneutics. Translated and edited by David Linge, U of California P, 1976.

---. Reason in the Age of Science. Translated by Frederick G. Lawrence, Massachusetts Institute of Technology P, 1979.

---. The Idea of the Good in Platonic-Aristotelian Philosophy. Translated by P.

Christopher Smith, Yale UP, 1986.

---. Truth and Method. Kindle ed., Continuum Publishing, 2004.

Green, Lelia. The Internet: An Introduction to New Media. Berg, 2010.

Gunkel, David J., and Paul A. Taylor. Heidegger and the Media. Polity P, 2014.

Hartley, John, Jean Burgess, and Axel Bruns, editors. A Companion to New Media Dynamics. John Wiley \& Sons, 2013.

Hinton, Sam, and Larissa Hjorth. Understanding Social Media. SAGE Publications Ltd, 2013.

Hofileña, Chay F. "Fake Accounts, Manufactured Reality on Social Media.” 9 Oct. 2016, http://www.rappler.com/newsbreak/investigative/148347-fake-accounts-manufactured-reality-social-media. Accessed 21 Nov. 2016.

Hornby, Susan, and Zoèe Clarke, editors. Challenge and Change in the Information Society. Facet, 2003.

Jenkins, Henry. Convergence Culture: Where Old and New Media Collide. New York UP, 2008.

---. "From Production to Produsage: Interview with Axel Bruns (Part One)." http:// henryjenkins.org/2008/05/interview_with_axel_bruns.html. Accessed 2 Aug. 2016.

Jenkins, Henry, Sam Ford, and James Green. Spreadable Media: Creating Value and Meaning in a Networked Culture. New York UP, 2013.

Karaganis, Joe, editor. Structures of Participation in Digital Culture. Social Science Research Council, 2007.

Lovink, Geert. Internet Without a Cause: A Critique of Social Media. Polity P, 2011.

---. Social Media Abyss: Critical Internet Culture and the Force of Negation. Polity P, 2016.

---. "What Is the Social in Social Media?” E-flux - Journal \#40 Dec. 2012. http:// www.e-flux.com/journal/40/60272/what-is-the-social-in-social-media/. Accessed 15 Feb. 2017.

Luttrell, Regina. Social Media: How to Engage, Share, and Connect. Rowmann \& Littlefield, 2015. 
Mansell, Robin. Imagining the Internet: Communication, Innovation, and Governance. Oxford UP, 2012.

McLuhan, Marshall. Understanding Media: The Extensions of Man [Critical Edition]. Edited by W. Terrence Gordon, Gingko P, 2003.

Meikle, Graham. Social Media: Communication, Sharing and Visibility. Routledge, 2016.

Miller, Vincent. Understanding Digital Culture. SAGE Publications Ltd., 2011.

Morozov, Evgeny. To Save Everything, Click Here: The Folly of Technological Solutionism. Public Affairs, 2013, p. ix.

Papacharissi, Zizi. "We Have Always Been Social." Social Media + Society, 17 April 2015 ? vol. 1 , no. 1 , pp. 1-2.

Rainie, Lee, and Barry Wellman. Networked: The New Social Operating System. Massachusetts Institute of Technology P, 2012.

Ressa, Maria A. "How Facebook Algorithms Impact Democracy.” 8 Oct. 2016, http://www.rappler.com/newsbreak/148536-facebook-algorithms-impact-democracy. Accessed 8 Sept. 2017.

---. "Propaganda War: Weaponizing the Internet." 3 Oct. 2016, http://www. rappler.com/nation/148007-propaganda-war-weaponizing-internet. Accessed 8 Sept. 2017.

Shapiro, Gary, and Alan Sica. Hermeneutics: Questions and Prospects. U of Massachusetts P, 1984.

van Dijck, Jose. Culture of Connectivity: A Critical History of Social Media. Kindle ed., Oxford UP, 2013.

Weller, Katrin, editor. Twitter and Society. Peter Lang, 2014.

Weiser, Mark. "The Computer for the 21st Century." Scientific American, Sept. 1991, pp. 94-104.

Wilhelm, Anthony G. Democracy in the Digital Age Challenges to Political Life in Cyberspace. Routledge, 2000.

Willnat, Lars, and Annette Aw. Social Media, Culture and Politics in Asia. Peter Lang, 2014. 